\section{D) Check for updates}

Cite this: Chem. Commun., 2020, 56,4037

Received 8th January 2020,

Accepted 23rd March 2020

DOI: $10.1039 / \mathrm{d} 0 \mathrm{cc} 00196 \mathrm{a}$

rsc.li/chemcomm

\title{
Gold nanomaterials functionalised with gadolinium chelates and their application in multimodal imaging and therapy
}

\author{
Hannah L. Perry, (D) ${ }^{\text {ab }}$ René M. Botnar (D) ${ }^{b}$ and James D. E. T. Wilton-Ely (D)*a
}

Over the last decade, much work has been dedicated to improving the performance of gadoliniumbased magnetic resonance imaging (MRI) contrast agents by tethering them to biocompatible gold nanoparticles. The enhancement in performance (measured in terms of 'relaxivity') stems from the restriction in motion experienced by the gadolinium chelates on being attached to the gold nanoparticle surface. More recently, the unique properties of gold nanoparticles have been exploited to create very promising tools for multimodal imaging and MRI-guided therapies. This review addresses the progress made in the design of gadolinium-functionalised gold nanoparticles for use in MRI, multimodal imaging and theranostics. It also seeks to connect the chemical properties of these assemblies with potential application in the clinic.

\section{Introduction}

Magnetic resonance imaging (MRI) is an extremely important tool in healthcare, used to detect and monitor a wide range of conditions, including cancer ${ }^{1}$ and cardiovascular disease. ${ }^{2}$ When a patient is placed in an MRI scanner, the magnetic moments of the ${ }^{1} \mathrm{H}$ nuclei in the body align themselves with the static magnetic field (either parallel or antiparallel), meaning that the overall macroscopic magnetisation points in the direction of the

\footnotetext{
${ }^{a}$ Molecular Sciences Research Hub, Department of Chemistry,

White City Campus, Imperial College London, London, W12 OBZ, UK.

E-mail: j.wilton-ely@imperial.ac.uk

${ }^{b}$ School of Biomedical Engineering and Imaging Sciences, King's College London, London, SE1 $7 E H, U K$
}

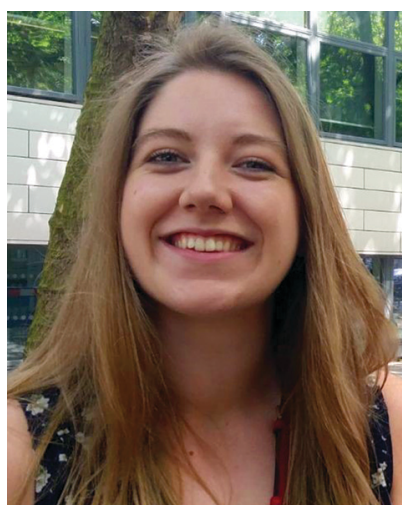

Hannah Perry received her MSci degree in Chemistry from the University of Birmingham before joining the EPSRC Centre for Doctoral Training in Smart Medical Imaging, where she is working towards her PhD. Hannah's research focuses on functionalised nanoparticles for the detection of atherosclerosis and cancer.

Hannah L. Perry

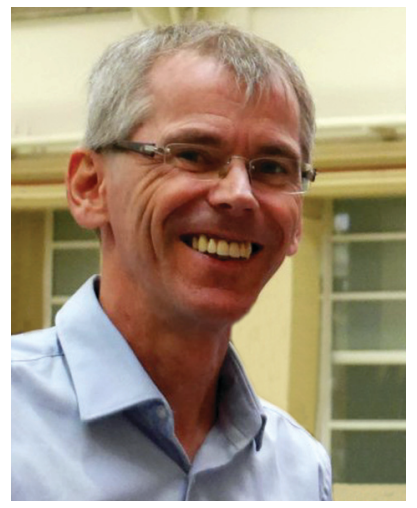

René Botnar's research interests include the development of MRI contrast agents for imaging atherosclerosis and myocardial infarction as well as MR pulse sequences for free-breathing, motion-corrected MRI. René is Chair of Cardiovascular Imaging and Head of Biomedical Engineering at King's College London. 
the 'relaxivity' and is used to judge the performance of a contrast agent. ${ }^{9}$ Commercial gadolinium-based contrast agents, such as Dotarem $^{\mathrm{TM}}$, consist of a $\mathrm{Gd}^{3+}$ ion encapsulated within a highly polydentate ligand. They achieve modest longitudinal $\left(T_{1}\right)$ relaxivities in the region of $4 \mathrm{mM}^{-1} \mathrm{~s}^{-1}$ at 1.5 Tesla (T) - a typical field strength for a clinical scanner - with higher relaxivity leading to a lighter image. ${ }^{10}$

Although there are many factors that affect the relaxivity of a gadolinium chelate, such as water exchange rate, $\mathrm{Gd} \cdots \mathrm{H}$ distance and hydration number (number of water ligands at the Gd centre), one of the most straightforward to manipulate is the rotational correlation time. ${ }^{11}$ As the gadolinium chelate rotates in solution, it creates a fluctuating magnetic field capable of inducing relaxation of local ${ }^{1} \mathrm{H}$ nuclei. ${ }^{12}$ By slowing the rotational motion of the chelate, the frequency of the fluctuating magnetic field falls to a value closer to the Larmor frequency, which results in a greater rate of relaxation. ${ }^{12}$ This restriction in rotational motion can be achieved by tethering the gadolinium chelates to a large structure, such as a nanoparticle. .,11 $^{-11}$

Gold nanoparticles have received much attention in the literature over the past twenty years due to their biocompatibility and tuneable morphology, which make them candidates for use in a wide range of clinical applications. ${ }^{13}$ Functionalisation of gold nanoparticles with gadolinium chelates to generate high-relaxivity MRI contrast agents is an active area of research, with over 180 research papers published since 2006. More recently, the focus has been directed toward developing these nanoparticles for use in multimodal imaging or combined therapy and imaging (theranostics). For example, the high atomic number of gold has been utilised to generate multimodal imaging agents capable of enhancing contrast in both MRI and computed tomography (CT), ${ }^{14}$ while gold nanorods have been functionalised with gadolinium chelates to create a theranostic agent for MRI-guided photothermal therapy. ${ }^{15}$

This review focuses on recent research on gadoliniumfunctionalised gold nanoparticles as MRI contrast agents but also seeks to illustrate their versatility as potential multimodal imaging and theranostic agents. The discussion has been divided into three parts, which focus on how the chemistry of the functionalised gold nanomaterials enables their use in an

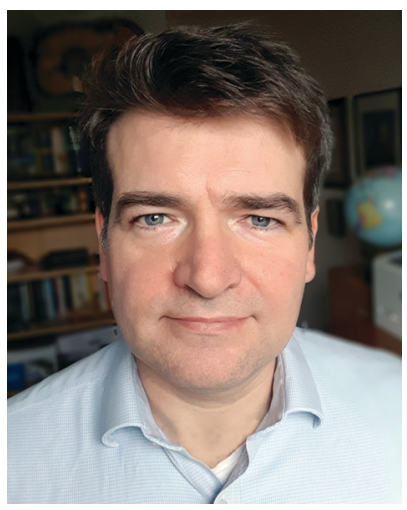

James Wilton-Ely leads a research group at Imperial College London investigating imaging, sensing and catalysis. A major focus is the synthesis and application of polymetallic molecular and nanoscale assemblies. These materials are being developed to address current challenges in bioimaging and sensing. He has authored more than 100 publications.

James D. E. T. Wilton-Ely

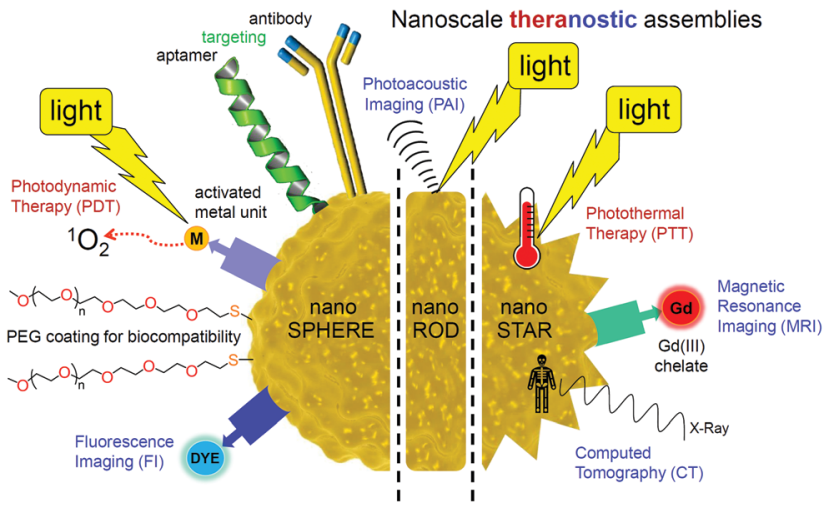

Fig. 1 Summary of the surface units and related applications of functionalised gold nanomaterials discussed in this review.

array of biological applications. The discussion begins by reviewing the factors that affect the relaxivity of gadoliniumfunctionalised gold nanoparticles, including the density of gadolinium loading and the rigidity of surface linkers. In the following sections, the discussion is extended to include multimodal imaging agents, in which MRI has been combined with additional imaging modalities such as CT, fluorescence and photoacoustic imaging. Finally, the development of theranostic agents, which employ MRI to guide interventions such as photothermal therapy (PTT), photodynamic therapy (PDT) and radiotherapy, is discussed. These approaches are summarised in Fig. 1 (image does not attempt to show all possible combinations of imaging and therapy).

\section{Discussion}

\section{High performance MRI contrast agents}

The enhancement in contrast produced in an MR image by a gadolinium-based contrast agent can be improved in two main ways: by boosting the relaxivity of the contrast agent or by increasing the gadolinium concentration (Fig. 2). Gadolinium chelates bound to gold nanoparticles are a particularly attractive prospect in the field of MRI because they exploit both of these factors. Tethering gadolinium chelates to a large structure, such as a nanoparticle, slows the rotational motion of the chelate ('slow tumbling') and thus boosts its relaxivity. ${ }^{16,17}$ Furthermore, nanoparticle-based approaches can exploit the enhanced

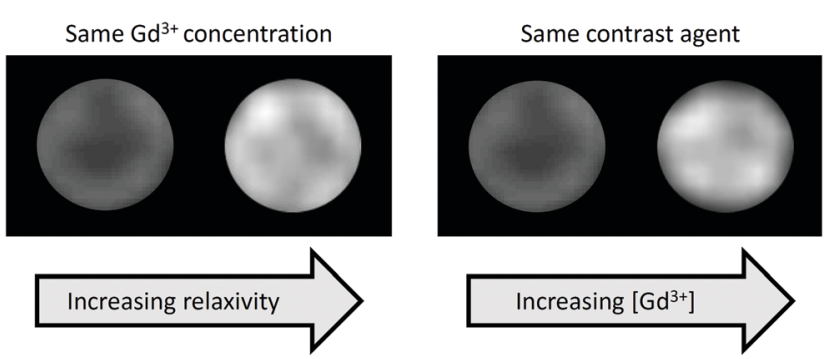

Fig. 2 Phantom MR images of Gd-based contrast agents illustrating contrast enhancement due to the effect of immobilisation on a nanoparticle surface (left) or increased Gd content (right). 
permeability and retention (EPR) effect, in which nanoscale materials accumulate in tumours. This effect can be traced to the characteristically leaky vasculature and poor lymphatic drainage of the tumour, causing greater accumulation of the nanostructure than in healthy tissue. With Gd-functionalised nanomaterials, this leads to increased gadolinium concentration in the tumour and hence better definition with respect to the surrounding, healthy tissue. ${ }^{18}$

The chelators developed for attaching $\mathrm{Gd}^{3+}$ to gold nanoparticles are largely based on clinically-approved chelators, such as 1,4,7,10-tetraazacyclododecane-1,4,7,10-tetraacetic acid (DOTA) and diethylenetriaminepentaacetic acid (DTPA) (Fig. 3). Earlier examples featured principally the DTPA chelator (Fig. 3A, C and D) due to its fast metal complexation kinetics and more straightforward synthetic derivation. ${ }^{19}$ More recently, however, the cyclic DOTA chelator (Fig. 3B and E-J) has been preferred due to its greater kinetic inertness, which stems from the ability of the rigid, pre-organised macrocyclic structure to encapsulate the $\mathrm{Gd}^{3+}$ ion more effectively than the acyclic DTPA chelator. $^{20}$ The irreversible encapsulation of gadolinium(III) is of paramount importance for the safe use of gadolinium in the body, as free $\mathrm{Gd}^{3+}$ is known to have a highly toxic effect due to its replacement of calcium(II) ions in the body, thus interfering with key biological processes. ${ }^{21}$ An association has also been found between the administration of Gd-based contrast agents and the development of nephrogenic systemic fibrosis (NSF) in patients with severe renal impairment. ${ }^{22}$ Unchelated $\mathrm{Gd}^{3+}$ ions form salts with endogenous anions, such as phosphate or carbonate, which then enter tissues, stimulating an inflammatory response and resulting in scarring of the tissue. ${ }^{23}$ Due to greater understanding of these effects and the implementation of regulatory guidance, gadolinium-related NSF is now uncommon. ${ }^{24}$

The high affinity of gold for polarisable, 'soft' donor atoms, explains the extensive use of sulfur-based linkers for attaching gadolinium chelates to the surface of gold nanoparticles. ${ }^{25}$ The incorporation of a thiol (or thiolate) moiety in the gadolinium chelate is the most straightforward and widespread method for binding the Gd unit to a gold nanoparticle. More recently, cyclic disulfides, which form dithiolates on attachment to the surface (Fig. 3G-I), ${ }^{26-28}$ and dithiocarbamates (Fig. 3J) ${ }^{29-31}$ have also been employed, as they provide a more secure two-site attachment. Furthermore, dithiocarbamates have been shown to displace thiols on gold nanoparticle surfaces but not vice versa, which further supports the robust nature of their binding to gold. ${ }^{32,33}$ The use of dithiocarbamates avoids issues encountered in designs based on two thiol groups (Fig. 3A), in which disulfide bridges can form as well as interactions with the gold surface, compromising the relaxivity values obtained. ${ }^{34}$

The choice of linker used to connect the sulfur unit to the gadolinium chelate also has a significant impact on relaxivity. If a chelate is bound to a nanoparticle using a long, flexible alkyl chain, the gadolinium chelate will experience substantial rotational freedom, compromising the beneficial effect on relaxivity of anchoring it to the surface. ${ }^{35}$ Longer linkers have also been found to have a detrimental impact on cellular uptake compared to shorter tethers. ${ }^{36}$ Shorter, more rigid linkers are thus favoured over long, flexible linkages, as can be seen in the designs depicted in Fig. 3. However, even gadolinium chelates anchored using relatively short linkers can experience substantial freedom of movement if the packing of the chelates on the nanoparticle surface is not sufficiently dense. ${ }^{28,37}$

Dense packing of gadolinium chelates on the nanoparticle surface further restricts the motion of the chelates and boosts relaxivity. ${ }^{38}$ Moreover, dense packing also helps prevent transmetallation of the $\mathrm{Gd}^{3+}$ ions by improving the thermodynamic stability and kinetic inertness of the gadolinium chelate. ${ }^{39}$ Meade et al. reported the dense packing of 2375 gadolinium chelates on the surface of individual $17 \mathrm{~nm}$ gold nanoparticles using a surface unit based on lipoic acid, forming a dithiolate attachment at the gold surface (Fig. $3 \mathrm{H}) .{ }^{27}$

Polymers are commonly added to the surface of nanoparticles to improve their stability towards aggregation and increase circulation time by camouflaging the nanoparticles from the body's immune system. ${ }^{40}$ The incorporation of polymers onto the nanoparticle surface has been known to both improve and hinder the relaxivity of a surface-bound Gd chelate. In the majority of cases, relaxivity decreases on the addition of a polymer surface coating as the polymer restricts the access of water to the gadolinium centres. ${ }^{41}$ However, in some cases, it appears that the polymer restricts the motion of the gadolinium chelates in the same way as dense packing of the gadolinium chelates, leading to an improvement in the relaxivity. ${ }^{42}$ These competing effects on relaxivity have also been observed when appending sugars to the surface of gold nanoparticles via linkers of differing lengths. ${ }^{43}$

The presence of a large payload of gadolinium ions per nanoparticle is a desirable quality of nanoparticle-based MRI contrast agents, as it enables a high concentration of gadolinium to be confined to a small area (Fig. 2). This results in a greater number of water molecules interacting with gadolinium and thus a greater contrast enhancement. ${ }^{44}$ Covalently binding gadolinium chelates to polymer coatings, rather than directly to the gold surface, has proved to be an effective method for increasing the number of gadolinium units per nanoparticle. ${ }^{45}$ DNA strands, in particular, have enabled hundreds of gadolinium chelates to be incorporated into each gold nanoparticle assembly. ${ }^{26,46-48}$ While the presence of many gadolinium units is often an advantage, it is the overall relaxivity that remains the broader goal. Through the rational design of the nanomaterial surface units and chelates, dramatic increases can be made in the relaxivity of individual gadolinium chelates, leading to improved contrast enhancement.

Polyethylene glycol (PEG), is a polymer widely used to stabilise gold nanoparticles and render them biocompatible. The PEG units play a key role in the function of a recent 'smart' MRI contrast agent developed by Li et al. that senses tumour microenvironments based on their increased acidity compared to healthy tissue. ${ }^{49}$ As the pH decreases, the PEG coating detaches from the gold nanoparticle surface to reveal alkyne and azide surface groups, which react via a metal-free 'click' cycloaddition reaction to form large nanoparticle aggregates. Generation of the aggregates results in an increase in relaxivity and therefore greater contrast enhancement in the region of the tumour. The authors suggest that 

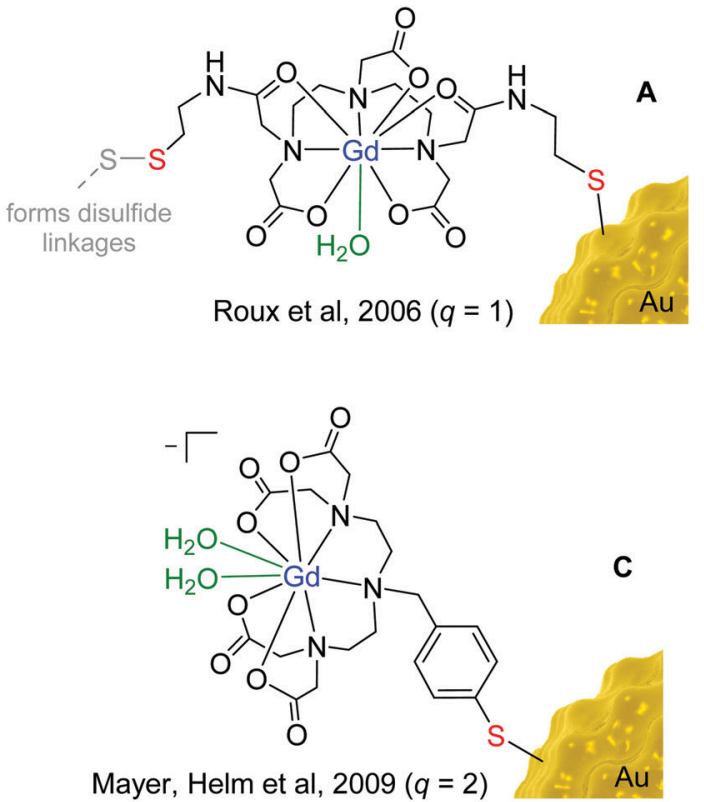
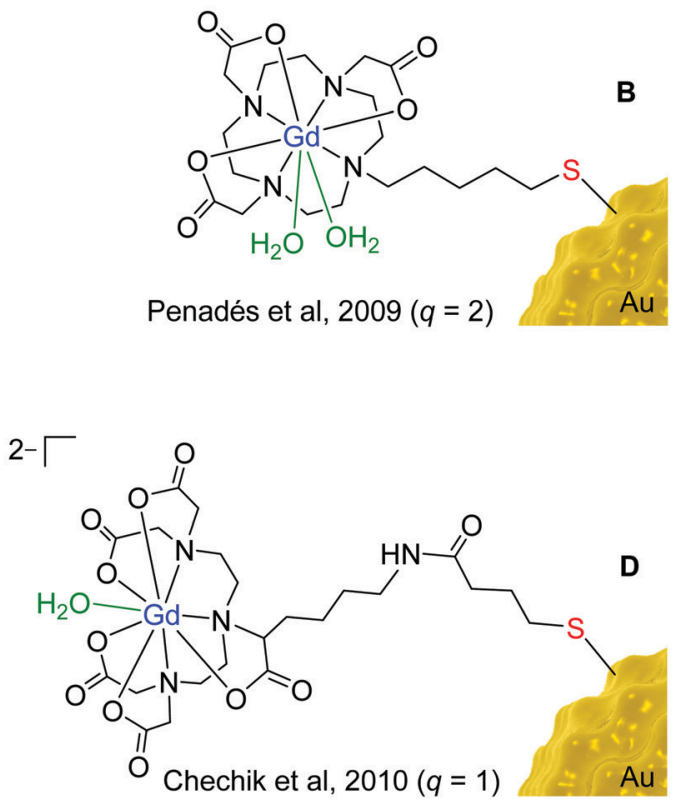
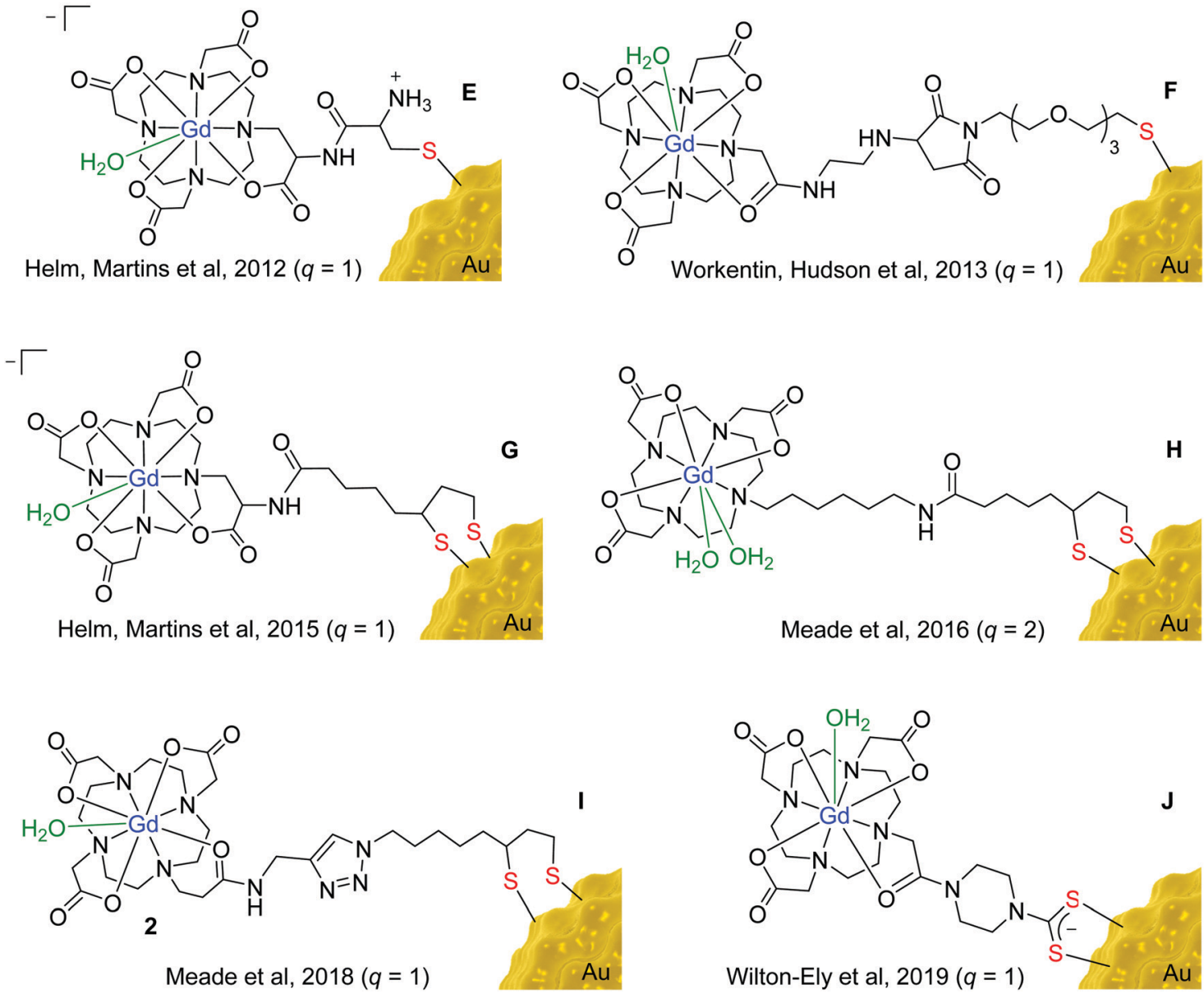

Fig. 3 Examples of gadolinium chelates used in functionalised gold nanomaterials.

this nanoparticle design could be valuable in guiding brain tumour surgery, where accurate assessment of the margins of the tumour is extremely important. ${ }^{49}$
Although nanoparticles are known to accumulate preferentially in tumours over healthy tissue due to the EPR effect (vide supra), targeting units are still utilised, either to complement the EPR 
effect or target the nanoparticles to an alternative disease to cancer. A vast array of targeting moieties, including small molecules, ${ }^{50}$ peptides, ${ }^{51}$ aptamers $^{52}$ and antibodies ${ }^{53}$ have been applied to the surface of gold nanoparticles to enhance the concentration of gold (and therefore gadolinium) at the target site. The modular approach inherent to nanoparticle-based designs, in contrast to most molecular agents, means that modification of the nanoparticle to target a different disease or cell type can be achieved without the need to make significant changes to the overall assembly.

\section{Multimodal imaging agents}

In multimodal imaging, complementary imaging modalities are combined to create single images that are immensely rich in information. ${ }^{54}$ The most widely-used form of multimodal imaging is PET/CT (positron emission tomography/computed tomography), which is primarily employed to stage the progression of different cancers by taking into account the morphology (CT) and metabolism (PET) of the tumour. ${ }^{55}$ To facilitate multimodal imaging, multimodal imaging agents have been developed that are capable of enhancing contrast in more than one type of scan. A major benefit of using a multimodal agent, compared to administering multiple imaging agents separately, is that any issues with differing biodistributions or biological half-lives are avoided. ${ }^{56}$

Gold nanoparticles are attractive as a basis for novel multimodal imaging agents due to the ease with which multiple imaging agents can be incorporated onto the same gold surface through sulfur-based tethers. In contrast, agents based on molecular assemblies often require significant design modifications in order to introduce new moieties into the structure, complicating the synthetic procedure. A further benefit of using gold nanoparticles in particular (over alternative nanomaterials) is that the gold nanostructure can itself act as an imaging agent for computed tomography (CT), photoacoustic imaging (PAI) and fluorescence imaging, without the need for any additional surface functionalisation (Fig. 4).

The contrast in CT is derived from the ability of hard tissues to absorb X-ray radiation to a greater degree than soft tissues. Typically, CT contrast agents are based on iodine, which, due to its electron-dense nature, absorbs more X-ray radiation than bodily tissues and therefore generates a positive contrast enhancement in regions of agent accumulation. Iodine-based agents, however, suffer from very short imaging times due to their rapid clearance by the kidneys, where they are associated with renal toxicity. ${ }^{57}$ Phantom imaging of equimolar solutions of gold nanoparticles and Omnipaque ${ }^{\mathrm{TM}}$, a clinically-used iodinebased CT imaging agent, revealed that the nanoparticles were able to generate a greater contrast enhancement due to the higher atomic mass of gold compared to iodine. ${ }^{58}$ This aspect, in addition to the reputation of gold nanoparticles for biocompatibility, makes gold nanoparticles an appealing alternative to the widely-used, iodine-based CT agents.

Gold nanomaterials that have been functionalised with gadolinium chelates have all the components necessary to provide contrast enhancement in both MRI and CT. Unlike combined PET/CT imaging, the approach of combining MRI

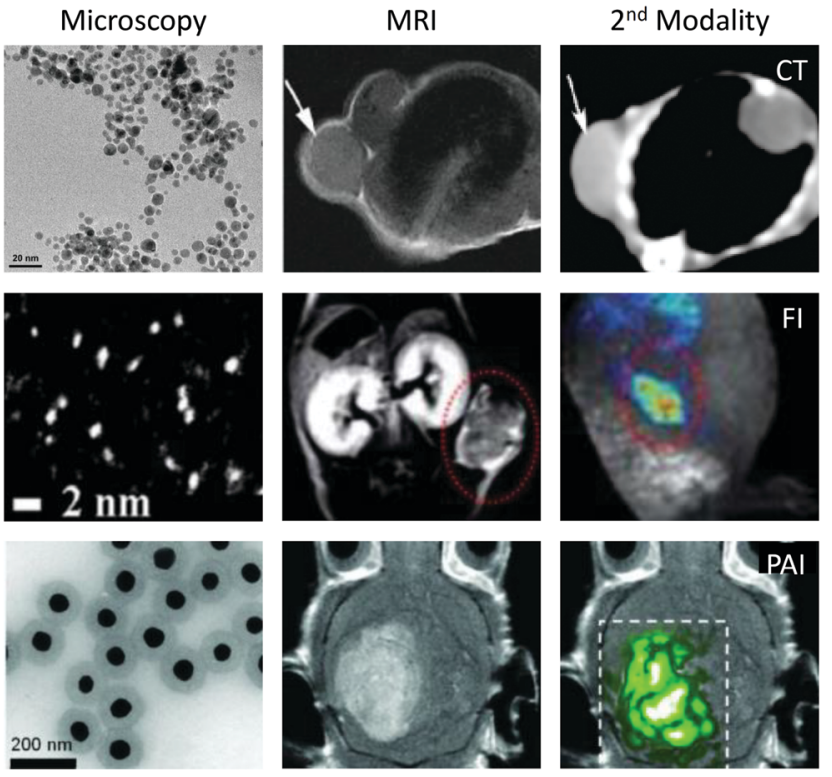

Fig. 4 Examples of MRI/CT, MRI/FI and MRI/PAI techniques performed using functionalised gold nanomaterials. Images reproduced from ref. 62 , with permission from Dove Press, ref. 70, with permission from the Royal Society of Chemistry, and ref. 68, with permission from Springer Nature.

and CT scans has not yet gained popularity in the clinic. At present, the usual scenario is for the patient to first receive a CT scan (by far the cheaper imaging modality) and then only being offered an MRI scan if the results from the CT were inconclusive. ${ }^{59}$ Despite this, there are a number of examples of gadolinium-functionalised gold nanomaterials being used to image tumours in vivo using both CT and MRI. ${ }^{59-62}$ The benefit of using the same multimodal agent for both scans is that the same biodistribution of the agent can be assumed, which aids comparison of the two images.

In addition to their application as CT imaging agents, gold nanomaterials have been used in photoacoustic imaging (PAI) to detect diseases such as atherosclerosis and cancer. ${ }^{63}$ PAI utilises the 'photoacoustic effect', which is the ability of a chromophore to convert absorbed light into heat energy, resulting in rapid expansion and then contraction of the chromophore, generating an acoustic wave. Gold nanomaterials are excellent candidates for PAI agents as their absorption wavelengths can be tuned away from the visible region of the electromagnetic spectrum, where endogenous chromophores are known to absorb, and towards the 'biological window' at approximately $800 \mathrm{~nm}$ (nearinfrared region). ${ }^{64,65}$ This reduces the level of unwanted background signal and allows increased penetration depth through the use of incident light of longer wavelength.

The absorption wavelength of gold nanorods can be tuned to the near-infrared region by manipulating their aspect ratio (the ratio of length to width). For example, by increasing the aspect ratio of a gold nanorod from 4.6 to 13, the wavelength of absorbed light increases from $885 \mathrm{~nm}$ to $1750 \mathrm{~nm} .{ }^{66}$ A gold nanorod with surface-bound gadolinium chelates and an aspect ratio of 3.1 was synthesised by Xing et al. for use as a combined $\mathrm{MRI} / \mathrm{PAI}$ agent and was found to absorb light at $710 \mathrm{~nm}$ and 
have a respectable relaxivity of $11.7 \mathrm{mM}^{-1} \mathrm{~s}^{-1}$ per Gd unit at $1.5 \mathrm{~T}^{67}$ Interestingly, the addition of a layer of gadolinium oxysulfide (GOS) to gold nanorods with an aspect ratio of 2.2 increased the absorption wavelength of the nanorods from $700 \mathrm{~nm}$ (without GOS) to $818 \mathrm{~nm}$ (20 nm thick GOS layer). ${ }^{64}$

Although it is advantageous to perform PAI using light in the near-infrared region, photoacoustic images of a murine brain tumour have been successfully acquired using a $532 \mathrm{~nm}$ laser. ${ }^{68}$ Despite the significant photoacoustic signal due to endogenous tissues, a $75 \%$ increase in overall photoacoustic signal was recorded following administration of the nanoparticles due to their very high absorption coefficient. In addition, the multilayered, core-shell gold nanomaterials used displayed impressive relaxivity values of $38 \mathrm{mM}^{-1} \mathrm{~s}^{-1}$ per Gd unit at $7 \mathrm{~T}$. This equates to an overall relaxivity of $3 \times 10^{6} \mathrm{mM}^{-1} \mathrm{~s}^{-1}$ due to the vast number of gadolinium chelates attached to each nanostructure. ${ }^{68}$ This relaxivity value is far greater than is typically achieved by gadolinium-based contrast agents at a magnetic field strength as high as $7 \mathrm{~T}$.

The fluorescent properties of gold nanoclusters have been coupled with the paramagnetic nature of $\mathrm{Gd}^{3+}$ ions to generate multimodal agents that combine the sensitivity of fluorescence imaging (FI) with the spatial resolution of MRI. ${ }^{69,70}$ Gold nanoclusters comprising just 25 gold atoms have been found to fluoresce with an emission wavelength of $640 \mathrm{~nm},{ }^{71}$ which is ideal for in vivo imaging, as it avoids the region between 400 and $570 \mathrm{~nm}$, in which the bulk of endogenous chromophores emit (autofluorescence). ${ }^{72}$ Furthermore, the addition of gadolinium chelates to the nanocluster did not affect the fluorescence intensity and resulted in a relaxivity of $23.7 \mathrm{mM}^{-1} \mathrm{~s}^{-1}$ per $\mathrm{Gd}$ unit at $1.5 \mathrm{~T}^{71}$

The facile manner in which gold nanomaterials can be functionalised means that weakly or non-fluorescent gold nanostructures are easily modified for use in fluorescence imaging through the addition of surface-bound dyes. ${ }^{73}$ These and other additional surface units are summarised in Table 1. Cyanine Cy5 is a popular choice in fluorescence imaging due to its bright fluorescence emission at $698 \mathrm{~nm}$. This avoids both the tissue absorption window and the absorption wavelength of gold, thus preventing immediate reabsorption of the fluorescence by either endogenous tissues or the gold nanoparticles. ${ }^{74}$ A 'smart' rhodamine-based dye, which emits fluorescence of variable intensity depending on local $\mathrm{pH}$, has also been tethered to gold nanoparticles for use in cancer imaging. ${ }^{75}$ Interestingly, the sensitivity of the dye to changes in $\mathrm{pH}$ conditions was found to increase on binding to the gold nanoparticle surface, possibly due to the large variation in surface charge experienced by the gold nanoparticles at $\mathrm{pH}$ values between 5.2 and $7.8 .^{75}$

Gold nanoparticles have also been used as a platform to combine MRI and single photon emission computed tomography (SPECT) imaging agents. DOTA-based chelators designed to encapsulate $\mathrm{Gd}^{3+}$ ions can also be used to achieve the complexation of ${ }^{67} \mathrm{Ga}^{3+}$ ions. ${ }^{76}$ Furthermore, this approach can be extended to the complexation of therapeutic radionuclides, thus widening the application of these nanoplatforms to include theranostics. ${ }^{76}$

\section{Theranostic agents}

MRI contrast agents are increasingly being combined with therapeutic moieties to generate 'theranostic' agents for use in image-guided therapies. Employing a theranostic approach to treating disease is extremely valuable in the development of 'personalised' medicine as it enables treatment plans to be tailored to the individual based on the images acquired before, during and after the treatment process. The aim of theranostic agents is to improve the efficacy of therapies by providing clinicians with realtime information on the biodistribution of the drug within the body as well as the progress of the treatment.

An active area of research is the development of theranostic agents for combined MRI and cancer therapy. Current cancer treatments are intrusive and often involve a combination of surgery, chemotherapy and radiotherapy. Photothermal therapy (PTT) is a more recent, minimally-invasive cancer treatment that causes localised cell death by radiation-induced hyperthermia. ${ }^{77}$ Gold nanostructures that exhibit a localised surface plasmon resonance, such as gold nanorods, can be employed as PTT agents as they are able to convert absorbed near-infrared radiation into heat energy. ${ }^{78-81}$ Functionalisation of the gold nanostructures with gadolinium chelates allows the creation of a theranostic agent for combined PTT and MRI (Fig. 5). ${ }^{15,82}$

Gold nanorods require careful surface functionalisation to prevent aggregation and avoid the presence of residual surface units from the synthetic procedure. Traditionally, surfactants such as cetyltrimethylammonium bromide (CTAB) have been used to promote colloidal stability, however, non-toxic alternatives are required for in vivo applications. Aryal et al. used PEG as an

Table 1 Additional surface units used in the nanomaterials covered in this review

\begin{tabular}{|c|c|c|c|}
\hline Category & Surface unit & Purpose & Ref. \\
\hline Surface unit & Dendrimer & Increases Gd loading & 45 \\
\hline Surface unit & DNA & Increases Gd loading & $46-48$ \\
\hline Surface unit & PEG, alkyne, azide & pH-Sensitive combination & 49 \\
\hline Surface unit & PEG, Tween ${ }^{\circledR} 20$, BSPP & Increases stability & 84 \\
\hline Surface unit & Glucose & Improves solubility & 43 \\
\hline Surface unit & Dextran & Increases stability & 85 \\
\hline Imaging agent & Cy5 dye & Fluorescence imaging & 73 \\
\hline Imaging agent & Rhodamine-based dye & Fluorescence imaging & 75 \\
\hline Imaging agent & ${ }^{67} \mathrm{Ga}$ & SPECT imaging & 76 \\
\hline Therapeutic agent & Indocyanine green & Photothermal therapy & 92 \\
\hline Therapeutic agent & Graphene oxide & Photothermal therapy & 93 and 94 \\
\hline Therapeutic agent & Porphyrin & Photodynamic therapy & $95-98$ \\
\hline
\end{tabular}




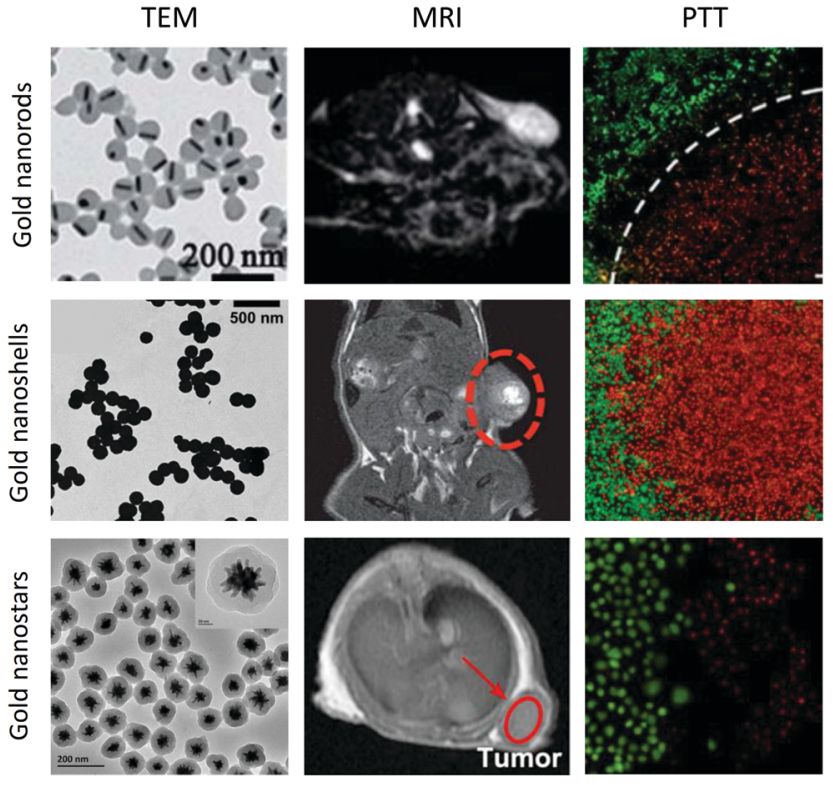

Fig. $5 \mathrm{MRI} / \mathrm{PTT}$ performed using functionalised gold nanorods, nanoshells and nanostars. Images reproduced from ref. 82, with permission from the Royal Society of Chemistry, ref. 88 , with permission from John Wiley $\&$ Sons, and ref. 89, with permission from Elsevier

alternative to CTAB and investigated the effect of PEG chain length on heating efficiency in PTT; reporting a greater temperature increase for nanorods functionalised with 2 or $5 \mathrm{kDa}$ PEG chains than those functionalised with longer $10 \mathrm{kDa}$ PEG. ${ }^{83}$ The successful exchange of CTAB with PEG can been achieved through the use of Tween ${ }^{\mathbb{R}} 20$ (to stabilise the nanorods) and bis( $p$-sulfonatophenyl)phenylphosphine (to activate the nanorod surface towards PEGylation). ${ }^{84}$ Dextran is a branched polysaccharide that may serve as a more favourable option than PEG for use in PTT, as it has been found to promote colloidal stability whilst limiting the impact on heating efficiency. ${ }^{85}$

Functionalised gold nanoshells have also been proposed as potential theranostic MRI and PTT agents. ${ }^{86} \mathrm{~A}$ multi-layer nanosphere consisting of a gold core, silica layer and gold shell was found to display an absorption peak at around $800 \mathrm{~nm}$, indicating suitability for PTT, and a relaxivity of up to $24 \mathrm{mM}^{-1} \mathrm{~s}^{-1}$ at $4.7 \mathrm{~T}^{87}$ Silica-gold core-shell nanoparticles that absorb at $800 \mathrm{~nm}$ have also been synthesised with an orthopyridyl disulfide linker to allow attachment of gadolinium chelates to the gold surface, thereby achieving a relaxivity of $37 \mathrm{mM}^{-1} \mathrm{~s}^{-1}$ per Gd unit at $1.41 \mathrm{~T}$ for these multi-layer nanoparticles. ${ }^{88}$

Gold nanostars, so called due to their spiked appearance, have been used in vitro and preclinically as near-infraredabsorbing PTT agents. ${ }^{89}$ For example, using a gold concentration of $20 \mu \mathrm{g} \mathrm{mL}^{-1}, 5$ minutes of irradiation at $808 \mathrm{~nm}$ was sufficient to reduce the percentage viability of MDA-MB-231 breast cancer cells to just $10 \%{ }^{89}$ Furthermore, the relaxivities of gadolinium chelates attached to nanostars are often far greater than equivalent nanosphere constructs. Vo-Dinh et al. achieved a relaxivity of $63.8 \mathrm{mM}^{-1} \mathrm{~s}^{-1}$ per Gd chelate at $1.5 \mathrm{~T}$ for $100 \mathrm{~nm}$ diameter nanostars loaded with over 64200 gadolinium chelates per nanostar. ${ }^{90}$ Meade, Hersam, Odom et al. further investigated this phenomenon by comparing functionalised nanostars with functionalised nanospheres and found that it was the number of spikes per nanostar that correlated with the boost in relaxivity, rather than simply nanoparticle size. ${ }^{91}$

Functionalisation of gold nanospheres with gadolinium chelates and near-infrared absorbers, such as indocyanine green and graphene oxide, has also proved to be an effective way of generating MRI/PTT agents. ${ }^{92-94}$ These highly functionalised gold nanospheres demonstrated a PTT effect similar in efficacy to the nanorods, nanoshells and nanostars while bypassing the need for strict control over the nanoparticle morphology. The combination of a Gd unit and a near-infrared absorber provides the functionality required to identify the location of the assembly using MRI before initiating the photothermal effect. This reduces collateral damage and increases the likelihood of a successful therapeutic outcome. Photosensitizers used in photo dynamic therapy (PDT) have also been attached to gold nanomaterials to allow delivery of localised cancer treatment through the generation of singlet oxygen. ${ }^{95-98}$ A particularly noteworthy example featured a photosensitizer attached to a gadolinium-functionalised gold nanoshell for combined MRI, CT, PTT and PDT. ${ }^{97}$ This approach highlighted the potential for gold nanomaterials to incorporate a combination of therapies into the same assembly, thereby augmenting the therapeutic potency. The ease with which this can be achieved relies heavily on the existing and well-established approaches developed for the generation and functionalisation of gold nanostructures.

In addition to their use as PTT agents, gold nanomaterials have also shown promise in radiotherapy, as their electrondense nature makes them strong absorbers of high frequency electromagnetic radiation. ${ }^{99}$ Radiotherapy is a cancer treatment, commonly used alongside chemotherapy, in which X-ray or gamma radiation is used to cause destruction of cancerous tissue. Large atoms, such as gold, improve the efficacy of radiotherapy by absorbing the X-ray or gamma radiation, consequently ejecting an Auger electron, which causes cell death in local tissue through ionisation and radical formation. ${ }^{100}$ In a number of in vivo studies, the increase in tumour volume was reduced and survival times increased when gold nanoparticles were used in radiotherapy, compared to when radiotherapy was performed in the absence of gold. ${ }^{101,102}$ This could have significant implications in the clinic as it would enable the same result to be achieved with a reduced radiation dose, which is particularly important for radio-sensitive organs like the brain. However, the impact of gold on the efficacy of radiotherapy is strongly dependent on the concentration of gold in the target tissue. ${ }^{103}$ Functionalisation of gold nanomaterials with gadolinium enables the level of nanoparticle accumulation to be assessed by MRI prior to treatment. Such an approach would ensure that the nanoparticles have maximum impact during radiotherapy. ${ }^{102}$

\section{Conclusions and outlook}

While gold nanomaterials have been investigated for many years, their applications in medical imaging and therapy are 
only now being realised. The recent developments highlighted here are an important part of this trend and suggest a bright future for gadolinium-functionalised gold nanomaterials in MRI, multimodal imaging and theranostics. As MRI contrast agents, these materials consistently out-perform the molecular complexes used in the clinic, largely due to the restriction in motion they impart on the surface-bound gadolinium chelates. In contrast to the non-specific biodistribution of current contrast agents, the modular design of the nanoparticle surface architecture also allows targeting to be achieved. As multimodal imaging agents, gold-based nanomaterials have shown great potential, particularly in cancer imaging, allowing the spatial resolution of MRI to be combined with the sensitivity of other modalities to generate clear and information-rich medical images. Furthermore, their use as a platform for pairing MRI with therapy introduces a powerful concept that will undoubtedly lead to more effective treatments in the future and better prognosis for patients. Through selected examples, this review has illustrated the rich versatility of these nanomaterials, in terms of size, shape and functionalisation. Although much has been achieved, there is still great scope for further development of multimodal and theranostic gold nanomaterials functionalised with gadolinium units. Of course, a limitation of using nanoparticles over low molecular weight agents is their more complex pharmacokinetics, which makes regulatory approval more challenging. The great variety that exists among gold nanomaterial formulations also complicates the approval pathway as changes in the size and functionalisation of gold nanostructures can influence their behaviour dramatically in vivo. For this reason, the approach to nanoparticles followed, for example, by the US Food and Drug Administration (FDA), is to avoid a categorical decision on the safety of nanomaterials but instead assess each new formulation independently. The successful clinical trials ${ }^{104,105}$ for the PTT agent, AuroLase $\mathrm{TM}^{\mathrm{TM}}$, and the protein-functionalised anti-cancer agent, Aurimmune ${ }^{\mathrm{TM}}$, point towards the great potential for clinical translation of multifunctional, theranostic nanostructures based on gold.

\section{Conflicts of interest}

There are no conflicts to declare.

\section{Acknowledgements}

The authors would like to acknowledge the EPSRC Centre for Doctoral Training in Smart Medical Imaging (King's College London and Imperial College London, EP/L015226/1) for the studentship held by H. L. P.

\section{References}

1 Z. Zhou and Z.-R. Lu, Wiley Interdiscip. Rev.: Nanomed. Nanobiotechnol., 2013, 5, 1-18.

2 G. Constantine, K. Shan, S. D. Flamm and M. U. Sivananthan, Lancet, 2004, 363, 2162-2171.

3 M. M. Britton, Chem. Soc. Rev., 2010, 39, 4036-4043.
4 J. Estelrich, M. J. Sánchez-Martín and M. A. Busquets, Int. J. Nanomed., 2015, 10, 1727-1741.

5 D. P. Cormode, B. L. Sanchez-Gaytan, A. J. Mieszawska, Z. A. Fayad and W. J. M. Mulder, NMR Biomed., 2013, 26, 766-780.

6 L. M. De Leon-Rodrıguez, A. F. Martins, M. C. Pinho, N. M. Rofsky and A. D. Sherry, J. Magn. Reson. Imaging, 2015, 42, 545-565.

7 A. Borel, J. F. Bean, R. B. Clarkson, L. Helm, L. Moriggi, A. D. Sherry and M. Woods, Chem. - Eur. J., 2008, 14, 2658-2667.

8 L. Granato, L. Vander Elst, C. Henoumont, R. N. Muller and S. Laurent, Chem. Biodiversity, 2018, 15, 1-16.

9 P. Caravan, A. V. Astashkin and A. M. Raitsimring, Inorg. Chem., 2003, 42, 3972-3974.

10 P. Hermann, J. Kotek, V. Kubicek and I. Lukes, Dalton Trans., 2008, 3027-3047.

11 M. Bottrill, L. Kwok and N. J. Long, Chem. Soc. Rev., 2006, 35, 557-571.

12 V. Jacques, S. Dumas, W.-C. Sun, J. S. Troughton, M. T. Greenfield and P. Caravan, Invest. Radiol., 2010, 45, 613-624.

13 E. C. Dreaden, A. M. Alkilany, X. Huang, C. J. Murphy and M. A. ElSayed, Chem. Soc. Rev., 2012, 41, 2740-2779.

14 H. Sun, Q. Yuan, B. Zhang, K. Ai, P. Zhang and L. Lu, Nanoscale, 2011, 3, 1990-1996.

15 A. Pitchaimani, T. D. T. Nguyen, L. Maurmann, J. Key, S. H. Bossmann and S. Aryal, J. Biomed. Nanotechnol., 2017, 13, 417-426.

16 J. Lux and A. D. Sherry, Curr. Opin. Chem. Biol., 2018, 45, 121-130.

17 M. Milne, P. Gobbo, N. McVicar, R. Bartha, M. S. Workentin and R. H. E. Hudson, J. Mater. Chem. B, 2013, 1, 5628-5635.

18 H. Samadian, S. Hosseini-Nami, S. K. Kamrava, H. Ghaznavi and A. Shakeri-Zadeh, J. Cancer Res. Clin. Oncol., 2016, 142, 2217-2229.

19 L. Frullano and P. Caravan, Curr. Org. Synth., 2011, 8, 535-565.

20 J. Lohrke, T. Frenzel, J. Endrikat, F. C. Alves, T. M. Grist, M. Law, J. M. Lee, T. Leiner, K.-C. Li, K. Nikolaou, M. R. Prince, H. H. Schild, J. C. Weinreb, K. Yoshikawa and H. Pietsch, Adv. Ther., 2016, 33, 1-28.

21 J.-M. Idee, M. Port, C. Robic, C. Medina, M. Sabatou and C. Corot, J. Magn. Reson. Imaging, 2009, 30, 1249-1258.

22 M. Rogosnitzky and S. Branch, Biometals, 2016, 29, 365-376.

23 J. M. Hazelton, M. K. Chiu and H. H. Abujudeh, Curr. Radiol. Rep., 2019, 7, 1-9.

24 H. Attari, Y. Cao, T. R. Elmholdt, Y. Zhao and M. R. Prince, Radiology, 2019, 292, 376-386.

25 E. Locatelli, I. Monaco and M. Comes Franchini, RSC Adv., 2015, 5, 21681-21699.

26 M. W. Rotz, R. J. Holbrook, K. W. MacRenaris and T. J. Meade, Bioconjugate Chem., 2018, 29, 3544-3549.

27 R. J. Holbrook, N. Rammohan, M. W. Rotz, K. W. MacRenaris, A. T. Preslar and T. J. Meade, Nano Lett., 2016, 16, 3202-3209.

28 M. F. Ferreira, J. Gonçalves, B. Mousavi, M. I. M. Prata, S. P. J. Rodrigues, D. Calle, P. López-Larrubia, S. Cerdan, T. B. Rodrigues, P. M. Ferreira, L. Helm, J. A. Martins and C. F. G. C. Geraldes, Dalton Trans., 2015, 44, 4016-4031.

29 S. Sung, H. Holmes, L. Wainwright, A. Toscani, G. J. Stasiuk, A. J. P. White, J. D. Bell and J. D. E. T. Wilton-Ely, Inorg. Chem., 2014, 53, 1989-2005.

30 J. Sharma, R. Chhabra, H. Yan and Y. Liu, Chem. Commun., 2008, 2140-2142.

31 N. G. Chabloz, M. N. Wenzel, H. L. Perry, I.-C. Yoon, S. Molisso, G. J. Stasiuk, D. S. Elson, A. E. G. Cass and J. D. E. T. Wilton-Ely, Chem. - Eur. J., 2019, 25, 10895-10906.

32 E. R. Knight, N. H. Leung, A. L. Thompson, G. Hogarth and J. D. E. T. Wilton-Ely, Inorg. Chem., 2009, 48, 3866-3874.

33 Y. Zhao, W. Perez-Segarra, Q. Shi and A. Wei, J. Am. Chem. Soc., 2005, 127, 7328-7329.

34 P.-J. Debouttière, S. Roux, F. Vocanson, C. Billotey, O. Beuf, A. Favre-Réguillon, Y. Lin, S. Pellet-Rostaing, R. Lamartine, P. Perriat and O. Tillement, Adv. Funct. Mater., 2006, 16, 2330-2339.

35 M. Marradi, D. Alcantara, J. Martinez de la Fuente, M. L. Garcia-Martin, S. Cerdan and S. Penadés, Chem. Commun., 2009, 3922-3924.

36 N. Rammohan, R. J. Holbrook, M. W. Rotz, K. W. MacRenaris, A. T. Preslar, C. E. Carney, V. Reichova and T. J. Meade, Bioconjugate Chem., 2017, 28, 153-160.

37 M. F. Ferreira, B. Mousavi, P. M. Ferreira, C. I. O. Martins, L. Helm, J. A. Martins and C. F. G. C. Geraldes, Dalton Trans., 2012, 41, 5472-5475.

38 L. Moriggi, C. Cannizzo, E. Dumas, C. R. Mayer, A. Ulianov and L. Helm, J. Am. Chem. Soc., 2009, 131, 10828-10829. 
39 V. Mogilireddy, I. Déchamps-Olivier, C. Alric, G. Laurent, S. Laurent, L. Vander Elst, R. Muller, R. Bazzi, S. Roux, O. Tillement and F. Chuburu, Contrast Media Mol. Imaging, 2015, 10, 179-187.

40 M. A. Dobrovolskaia, P. Aggarwal, J. B. Hall and S. E. McNeil, Mol. Pharmaceutics, 2008, 5, 487-495.

41 B. Zhou, Z. Xiong, P. Wang, C. Peng, M. Shen, S. Mignani, J.-P. Majoral and X. Shi, Drug Delivery, 2018, 25, 178-186.

42 M. F. Warsi, R. W. Adams, S. B. Duckett and V. Chechik, Chem. Commun., 2010, 46, 451-453.

43 A. Irure, M. Marradi, B. Arnáiz, N. Genicio, D. Padro and S. Penadés, Biomater. Sci., 2013, 1, 658-668.

44 K. B. Ghaghada, M. Ravoori, D. Sabapathy, J. Bankson, V. Kundra and A. Annapragada, PLoS One, 2009, 4, 1-7.

45 Q. Chen, H. Wang, H. Liu, S. Wen, C. Peng, M. Shen, G. Zhang and X. Shi, Anal. Chem., 2015, 87, 3949-3956.

46 Y. Song, X. Xu, K. W. MacRenaris, X.-Q. Zhang, C. A. Mirkin and T. J. Meade, Angew. Chem., Int. Ed., 2009, 48, 9143-9147.

47 L. F. Vistain, M. W. Rotz, R. Rathore, A. T. Preslar and T. J. Meade, Chem. Commun., 2016, 52, 160-163.

48 F. J. Nicholls, M. W. Rotz, H. Ghuman, K. W. MacRenaris, T. J. Meade and M. Modo, Biomaterials, 2016, 77, 291-306.

49 X. Gao, Q. Yue, Z. Liu, M. Ke, X. Zhou, S. Li, J. Zhang, R. Zhang, L. Chen, Y. Mao and C. Li, Adv. Mater., 2017, 29, 1603917.

50 G. A. Mansoori, K. S. Brandenburg and A. Shakeri-Zadeh, Cancers, 2010, 2, 1911-1928.

51 Y. Yang, L. Zhang, J. Cai, X. Li, D. Cheng, H. Su, J. Zhang, S. Liu, H. Shi, Y. Zhang and C. Zhang, ACS Appl. Mater. Interfaces, 2016, 8, 1718-1732.

52 X. Wang, Q. Han, N. Yu, J. Li, L. Yang, R. Yang and C. Wang, J. Mater. Chem. B, 2015, 3, 4036-4042.

53 J. B. Otis, H. Zong, A. Kotylar, A. Yin, S. Bhattacharjee, H. Wang, J. R. Bàker Jr and S. H. Wang, Oncotarget, 2016, 7, 36002-36013.

54 J. Rieffel, U. Chitgupi and J. F. Lovell, Small, 2015, 11, 4445-4461.

55 R. Bar-Shalom, N. Yefremov, L. Guralnik, D. Gaitini, A. Frenkel, A. Kuten, H. Altman, Z. Keidar and O. Israel, J. Nucl. Med., 2003, 44, 1200-1209.

56 D.-E. Lee, H. Koo, I.-C. Sun, J. H. Ryu, K. Kim and I. C. Kwon, Chem. Soc. Rev., 2012, 41, 2656-2672.

57 J.-A. Park, H.-K. Kim, J.-H. Kim, S.-W. Jeong, J.-C. Jung, G.-H. Lee, J. Lee, Y. Chang and T.-J. Kim, Bioorg. Med. Chem. Lett., 2010, 20, 2287-2291.

58 B. Zhou, J. Yang, C. Peng, J. Zhua, Y. Tang, X. Zhua, M. Shena, G. Zhang and X. Shi, Colloids Surf., B, 2016, 140, 489-496.

59 B. Zhou, Z. Xiong, J. Zhu, M. Shen, G. Tang, C. Peng and X. Shi, Nanomedicine, 2016, 11, 1639-1652.

60 C. Alric, J. Taleb, G. Le Duc, C. Mandon, C. Billotey, A. Le MeurHerland, T. Brochard, F. Vocanson, M. Janier, P. Perriat, S. Roux and O. Tillement, J. Am. Chem. Soc., 2008, 130, 5908-5915.

61 R. Wang, Y. Luo, X. Li, A. Ji, R. Guo, X. Shi and X. Wang, J. Mater. Chem. B, 2018, 6, 1342-1350.

62 K. Li, S. Wen, A. C. Larson, M. Shen, Z. Zhang, Q. Chen, X. Shi and G. Zhang, Int. J. Nanomed., 2013, 8, 2589-2600.

63 J. L. Su, B. Wang, K. E. Wilson, C. L. Bayer, Y.-S. Chen, S. Kim, K. A. Homan and S. Y. Emelianov, Expert Opin. Med. Diagn., 2010, 4, 497-510.

64 T. Guo, Y. Lin, Z. Li, S. Chen, G. Huang, H. Lin, J. Wang, G. Liuc and H.-H. Yang, Nanoscale, 2017, 9, 56-61.

65 J. F. Hainfeld, M. J. O'Connor, P. Lin, L. Qian, D. N. Slatkin and H. M. Smilowitz, PLoS One, 2014, 9, 1-11.

66 N. R. Jana, L. Gearheart and C. J. Murphy, J. Phys. Chem. B, 2001, 105, 4065-4067.

67 H. Qin, T. Zhou, S. Yang, Q. Chen and D. Xing, Nanomedicine, 2013, 8, 1611-1624.

68 M. F. Kircher, A. de la Zerda, J. V. Jokerst, C. L. Zavaleta, P. J. Kempen, E. Mittra, K. Pitter, R. Huang, C. Campos, F. Habte, R. Sinclair, C. W. Brennan, I. K. Mellinghoff, E. C. Holland and S. S. Gambhir, Nat. Med., 2012, 18, 829-834.

69 G. Liang and L. Xiao, Biomater. Sci., 2017, 5, 2122-2130.

70 D.-H. Hu, Z.-H. Sheng, P.-F. Zhang, D.-Z. Yang, S.-H. Liu, P. Gong, D.-Y. Gao, S.-T. Fang, Y.-F. Ma and L.-T. Cai, Nanoscale, 2013, 5, 1624-1628.

71 G. Sun, L. Zhou, Y. Liu and Z. Zhao, New J. Chem., 2013, 37, 1028-1035.
72 A. C. Croce and G. Bottiroli, Eur. J. Histochem., 2014, 58, 320-337.

73 M. E. Gallina, Y. Zhou, C. J. Johnson, D. Harris-Birtill, M. Singh, H. Zhao, D. Ma, T. Cass and D. S. Elson, Mater. Sci. Eng., C, 2016, 59, 324-332.

74 M. M. van Schooneveld, D. P. Cormode, R. Koole, J. T. van Wijngaarden, C. Calcagno, T. Skajaa, J. Hilhorst, D. C. 't Hart, Z. A. Fayad, W. J. M. Mulder and A. Meijerink, Contrast Media Mol. Imaging, 2010, 5, 231-236.

75 C. J. Eling, T. W. Price, A. R. L. Marshall, F. N. Viscomi, P. Robinson, G. Firth, A. M. Adawi, J.-S. G. Bouillard and G. J. Stasiuk, ChemPlusChem, 2017, 82, 674-680.

76 F. Silva, A. Paulo, A. Pallier, S. Même, É. Tóth, L. Gano, F. Marques, C. F. G. C. Geraldes, M. M. C. A. Castro, A. M. Cardoso, A. S. Jurado, P. López-Larrubia, S. Lacerda and M. P. C. Campello, Materials, 2020, 13, 513-530.

77 E. B. Dickerson, E. C. Dreaden, X. Huang, I. H. El-Sayed, H. Chu, S. Pushpanketh, J. F. McDonald and M. A. El-Sayed, Cancer Lett., 2008, 269, 57-66.

78 X. Huang, I. H. El-Sayed, W. Qian and M. A. El-Sayed, J. Am. Chem. Soc., 2006, 128, 2115-2120.

79 H.-H. Chang and C. J. Murphy, Chem. Mater., 2018, 30, 1427-1435.

80 M. A. Mackey, M. R. K. Ali, L. A. Austin, R. D. Near and M. A. Elsayed, J. Phys. Chem. B, 2014, 118, 1319-1326.

81 H. N. Green, D. V. Martyshkin, C. M. Rodenburg, E. L. Rosenthal and S. B. Mirov, J. Nanotechnol., 2011, 1, 1-7.

82 C. Zhang, F. Zhang, W. Wang, J. Liu, M. Xu, D. Wu, X. Shuai, J. Shen and Z. Cao, RSC Adv., 2016, 6, 111337.

83 R. Marasini, A. Pitchaimani, T. D. T. Nguyen, J. Comer and S. Aryal, Nanoscale, 2018, 10, 13684-13693.

84 K. Liu, Y. Zheng, X. Lu, T. Thai, N. A. Lee, U. Bach and J. J. Gooding, Langmuir, 2015, 31, 4973-4980.

85 R. Choi, J. Yang, J. Choi, E. K. Lim, E. Kim, J. S. Suh, Y. M. Huh and S. Haam, Langmuir, 2010, 26, 17520-17527.

86 M. P. Melancon, W. Lu, Z. Yang, R. Zhang, Z. Cheng, A. M. Elliot, J. Stafford, T. Olson, J. Z. Zhang and C. Li, Mol. Cancer Ther., 2008, 7, 1730-1739.

87 V. S. Marangoni, O. Neumann, L. Henderson, C. C. Kaffes, H. Zhang, R. Zhang, S. Bishnoi, C. Ayala-Orozco, V. Zucolotto, J. A. Bankson, P. Nordlander and N. J. Halas, Proc. Natl. Acad. Sci. U. S. A., 2017, 114, 6960-6965.

88 A. J. Coughlin, J. S. Ananta, N. Deng, I. V. Larina, P. Decuzzi and J. L. West, Small, 2014, 10, 556-565.

89 Y. Gao, Y. Li, J. Chen, S. Zhu, X. Liu, L. Zhou, P. Shi, D. Niu, J. Gu and J. Shi, Biomaterials, 2015, 60, 31-41.

90 Y. Liu, Z. Chang, H. Yuan, A. M. Fales and T. Vo-Dinh, Nanoscale, 2013, 5, 12126-12131.

91 K. S. B. Culver, Y. J. Shin, M. W. Rotz, T. J. Meade, M. C. Hersam and T. W. Odom, J. Phys. Chem. C, 2016, 120, 22103-22109.

92 Y. Zeng, D. Zhang, M. Wu, Y. Liu, X. Zhang, L. Li, Z. Li, X. Han, X. Wei and X. Liu, ACS Appl. Mater. Interfaces, 2014, 6, 14266-14277.

93 X. Ma, Y. Jin, Y. Wang, S. Zhang, D. Peng, X. Yang and S. Wei W. Chai, X. Li and J. Tian, Contrast Media Mol. Imaging, 2018, 2018, 1-14.

94 L. Yang, Y. T. Tseng, G. Suo, L. Chen, J. Yu, W. J. Chiu, C. C. Huang and C. H. Lin, ACS Appl. Mater. Interfaces, 2015, 7, 5097-5106.

95 O. Penon, T. Patino, L. Barrios, C. Nogues, D. B. Amabilino, K. Wurst and L. Perez-Garcia, ChemistryOpen, 2015, 4, 127-136.

96 Y. Cheng, J. D. Meyers, A.-M. Broome, M. E. Kenney, J. P. Basilion and C. Burda, J. Am. Chem. Soc., 2011, 133, 2583-2591.

97 S. Yang, Q. You, L. Yang, P. Li, Q. Lu, S. Wang, F. Tan, Y. Ji and N. Li, ACS Appl. Mater. Interfaces, 2019, 11, 6777-6788.

98 N. G. Chabloz, H. L. Perry, I.-C. Yoon, A. J. Coulson, A. J. P. White, G. J. Stasiuk, R. M. Botnar and J. D. E. T. Wilton-Ely, Chem. - Eur. J., DOI: $10.1002 /$ chem.201904757.

99 D. Y. Joh, L. Sun, M. Stangl, A. Al Zaki, S. Murty, P. P. Santoiemma, J. J. Davis, B. C. Baumann, M. Alonso-Basanta, D. Bhang, G. D. Kao, A. Tsourkas and J. F. Dorsey, PLoS One, 2013, 8, 1-10.

100 K. T. Butterworth, J. R. Nicol, M. Ghita, S. Rosa, P. Chaudhary, C. K. McGarry, H. O. McCarthy, G. Jimenez-Sanchez, R. Bazzi, S. Roux, O. Tillement, J. A. Coulter and K. M. Prise, Nanomedicine, 2016, 11, 2035-2047.

101 C. Alric, R. Serduc, C. Mandon, J. Taleb, G. Le Duc, A. Le MeurHerland, C. Billotey, P. Perriat, S. Roux and O. Tillement, Gold Bull., 2008, 41, 90-97. 
102 I. Miladi, C. Alric, S. Dufort, P. Mowat, A. Dutour, C. Mandon, G. Laurent, E. Bräuer-Krisch, N. Herath, J. L. Coll, M. Dutreix, F. Lux, R. Bazzi, C. Billotey, M. Janier, P. Perriat, G. Le Duc, S. Roux and O. Tillement, Small, 2014, 10, 1116-1124.

103 N. Ma, F.-G. Wu, X. Zhang, Y.-W. Jiang, H.-R. Jia, H.-Y. Wang, Y.-H. Li, P. Liu, N. Gu and Z. Chen, ACS Appl. Mater. Interfaces, 2017, 9, 13037-13048.
104 A. R. Rastinehad, H. Anastos, E. Wajswol, J. S. Winoker, J. P. Sfakianos, S. K. Doppalapudi, M. R. Carrick, C. J. Knauer, B. Taouli, S. C. Lewis, A. K. Tewari, J. A. Schwartz, S. E. Canfield, A. K. George, J. L. West and N. J. Halas, Proc. Natl. Acad. Sci. U. S. A., 2019, 116, 18590-18596.

105 S. K. Libutti, G. F. Paciotti, A. A. Byrnes, H. R. J. Alexander, W. E. Gannon, M. Walker, G. D. Seidel, N. Yuldasheva and L. Tamarkin, Clin. Cancer Res., 2010, 16, 6131-6149. 